\title{
A continuous dynamic feature of the distribution of soil temperature and horizontal heat flux next to external walls in different orientations of construction sites in the autumn of Beijing, China
}

 \\ Xiaolin Wang a, Fengsen Han ${ }^{\mathrm{a}}$, Xiaoke Wang a, c \\ a State Key Laboratory of Urban and Regional Ecology, Research Center for Eco-Environmental Sciences, Chinese Academy of Sciences, Beijing 100085, PR \\ China \\ b Chinese Academy for Environmental Planning, Beijing 100012, PR China \\ ${ }^{\mathrm{c}}$ Beijing Urban Ecosystem Research Station, Research Center for Eco-Environmental Sciences, Chinese Academy of Sciences, Beijing 100085, PR China
}

\section{A R T I C L E I N F O}

\section{Article history:}

Received 3 March 2015

Received in revised form

8 October 2015

Accepted 26 October 2015

Available online 11 November 2015

\section{Keywords:}

Horizontal heat impact

Soil temperature

Horizontal heat flux

Construction

Ecotone

\begin{abstract}
A B S T R A C T
Soil is an important carrier of the urban ecosystem. Many eco-systematic processes take place in the soil surface layer and are controlled directly by soil temperature. However, accelerated global urbanization and urban construction lead to urban heat islands, causing higher air temperatures in urban areas than those in rural areas. For the same reason, soil temperature is higher in urban areas. Higher soil temperatures may cause changes in eco-systematic processes. Therefore, studying and understanding how soil temperature changes in urban areas is necessary. In other words, the heat impact from urban construction, including its process and extent, on soil needs further researches. In this study, the experimental transect was arranged in the ecotone between construction and green space. The temperature of the surface soil layer was investigated and recorded to analyze urban construction horizontal heat impact process and quantity on the soil of green space in urban areas during autumn within Beijing city, China. Several acquired results are as follows: in autumn, downward-trend distributions of soil temperature were found along the construction-soil micro gradient transect next to the south, north, east and west side external walls. The south, north, east and west side external walls' maximum horizontal heat impact scopes are $0.15,0.0167,0.1$ and $0.05 \mathrm{~m}$, respectively, on a diurnal scale. The daily horizontal heat impact process was different along the experimental transect, changing with orientation of the building external wall. According to continuous investigation, a formulation of horizontal heat flux ( $\mathrm{G}_{\mathrm{h}}$, between buildings and soil) and $\Delta \mathrm{T}$ (difference between soil temperature 0 and $0.05 \mathrm{~m}$ from the building baseline) was generated: $\mathrm{G}_{\mathrm{h}}=31.77 \Delta \mathrm{T}+8.11(\mathrm{P}<0.0001)$, where $\mathrm{R}^{2}$ was 0.976 . In addition, no significant difference $(\mathrm{P}>0.05)$ was found between the value of simulation and measurement via a twotailed $\mathrm{T}$ test. Based on this formulation, a continuous dynamic-feature for heat flux was calculated. On a diurnal scale, the mean horizontal heat flux at different orientations of external walls for both sunny and cloudy days are as follows: 44.13 and $7.07 \mathrm{~W} / \mathrm{m}^{2}$ for south, 28.15 and $9.22 \mathrm{~W} / \mathrm{m}^{2}$ for north, 21.44 and $9.66 \mathrm{~W} / \mathrm{m}^{2}$ for east and 24.42 and $13.54 \mathrm{~W} / \mathrm{m}^{2}$ for west. Downward gradient distributions of mean horizontal heat flux of autumn were calculated; for south, north, east and west side external walls, the maximum was $29.94,25.44,24.87$ and $23.50 \mathrm{~W} / \mathrm{m}^{2}$ and the minimum was $7.31,6.46,7.45$ and $4.81 \mathrm{~W} / \mathrm{m}^{2}$. Therefore, construction sites were considered to be a heat source for soil and provided soil with thermal energy, leading to a higher soil temperature around construction sites in urban areas during autumn. This study focused on urban construction horizontal heat impacts on the soil of adjacent green space in conditions of different weather in autumn and helped us to understand the quantitative processes of horizontal heat impact. In addition, the study will benefit research examining the ecological relationships of urban heat islands and ecosystem processes.
\end{abstract}

๑) 2015 Elsevier Ltd. All rights reserved.

\footnotetext{
* Corresponding author.

E-mail address: hudan@rcees.ac.cn (D. Hu).
} 


\section{Introduction}

As an important carrier of the urban ecosystem, urban soil plays a crucial role in urban areas. Many soil ecological systematic processes take place at the soil surface layer; thus, the soil environment is relevant to many ecological systematic and biochemical processes. Soil temperature is a crucial factor to control these ecological systematic processes, such as soil heterotrophic respiration, microbial decomposition, nutrient cycling, and root respiration (Grimm et al., 2008; Pouyat et al., 2007). In addition, soil temperature variation impacts the engineering properties of urban soils. As a result, the strength and stability of various engineered structures change as the soil fluctuates. Many studies have indicated that an increase in shallow soil temperature influences soil permeability, suction of unsaturated soils, and soil shear strength (Jacinto et al., 2009; Tang and Cui, 2005). Therefore, soil temperature is relevant not only to urban ecological systematic process but also to municipal engineering.

Due to rapid urbanization around the world, a series of negative effects have emerged. Urban heat islands (UHI), one of these negative effects, is known as a phenomenon in which air temperature is higher in urban areas than that in rural areas (Landsberg, 1981; Oke, 1982). In reality, not only does the air temperature rise in urban areas but also do soil temperatures. So far, many studies have shown just this. The soil surface layer held a 3 K-higher temperature in the green space of a parking lot on a campus than the control groups (Halverson and Heisler, 1981). The soil temperature was 3.13-11.22 $\mathrm{K}$ higher than that in nearby forest in New York City (Mount et al., 1999). At vertical depths of 0.05, 0.1, 0.2 and $0.5 \mathrm{~m}$ in the city of Ankara, the soil temperature was $1.8-2.1 \mathrm{~K}$ higher than that of the rural area (Turkoglu, 2010). Furthermore, the city of Nanjing shared a similar situation as Ankara city, in which the mean soil temperature was $1.21-2.02 \mathrm{~K}$ higher than suburban areas (Shi et al., 2012; Tang et al., 2011). The above studies reported the phenomenon of higher soil temperatures in urban areas. The mechanism and reason for these increases in soil temperature need to be studied carefully.

In urban areas, buildings and roads are considered as heat sources for the soil, whereas soil is regarded as a heat sink. Soil plays a crucial role in keeping adjacent buildings from reaching overly high temperatures in Saudi Arabia and other hot regions (Givoni, 2007). Soil that was covered by asphalt has been found to be $10 \mathrm{~K}$ higher in temperature than controls groups (Halverson and Heisler, 1981). The regularity of soil temperature changes beneath constructions was revealed in a study that measured soil temperature in a constantly changing external environment, and an accurate model to predict soil temperature beneath constructions was developed on the basics of heat flow between constructions and soil (Mihalakakou et al., 1995). Quantitative heat transport between soil and an insulating layer with different materials was calculated, and good results were acquired (Landman and Delsante, 1987). Thermal energy transfer does not exist only between buildings and soil but also between roads and soil. Roads provided higher temperature to soil around and could endanger the roots of plants (Bogren and Gustavsson, 1991; Yang, 2006). Roads were considered as a heat source for its adjacent soil on islands, holding a relative higher temperature than its surrounding forest soil. The combined effect of both higher temperatures of roads and the canopy density of the forest contributed to a gradient distribution of soil temperature at the first $3 \mathrm{~m}$ along the transect between the roads and the forest (Delgado et al., 2007). Due to the heat impact of construction, soil temperature was higher. The horizontal heat flux between the construction and soil was one reason for the increased temperature. Many studies have reported building heat losses via soil and ground, and the previous study's aims were to save energy and research the indoor environment (Janssen et al., 2004; Simões and Serra, 2012). The heat flux between construction and soil has not been studied to analyze its impact on soil or its mechanism.

Based on the previous studies mentioned above, construction is indeed a factor that leads to higher soil temperatures in urban areas. Nevertheless, what type of horizontal distribution in soil temperature around buildings has not yet been studied. In addition, its dynamic process feature is still not known. Many fruitful studies on the vertical distribution of soil temperature in urban areas have been conducted (Tang et al., 2011; Turkoglu, 2010), whereas the horizontal distribution of soil temperature and the processes of the heat impact from construction is not yet clear. Here, horizontal is used to describe a spatial layout, as distinguished from vertical. Therefore, a series of continuous investigation and observation were conducted in this study to discover the horizontal distribution of soil temperature, the process of horizontal heat impact from constructions, and the distribution of horizontal heat flux around buildings.

\section{Site condition}

The research site is located in the Haidian District in Beijing City $\left(116.3374^{\circ} \mathrm{E}, 40.0077^{\circ} \mathrm{N}\right)$ and exhibited a loam soil texture. Beijing, the capital of China, is recognized as a metropolis around the world. It located between $115.7^{\circ} \mathrm{E}-117.4^{\circ} \mathrm{E}, 39.4^{\circ} \mathrm{N}-41.6^{\circ} \mathrm{N}$, belonging to a monsoon-influenced humid continental climate. Its solar radiation is in an average band of $112-136 \mathrm{kcal} / \mathrm{cm}^{2}$. In autumn, the sunshine duration is between 230 and 245 h per month in Beijing, with few rainy days. The observation data of this study were collected in the autumn of 2013, dated from 25/9/2013 to $15 / 10 /$ 2013.

Observation sites were selected at different orientations relative to the side external walls of buildings (Fig. 1a). The land cover and detailed conditions for the selected Observation sites is shown in Table 1. In each selected observation site, no macro phanerophytes were found but a few arbuscles were planted. Sunshine was not blocked by vegetation at the observation sites. The only factor that blocked sunshine was the building.

\section{Methods}

\subsection{Layout of construction-soil micro gradient transect and in situ observation}

The gradient method is widely applied to research ecological issues. It was applied to investigate urban ecosystem properties and then urban landscape patterns and the ecological consequences of the urbanization process (Luck and Wu, 2002; Pouyat and McDonnell, 1991; Pouyat et al., 1995; Zhu and Carreiro, 1999). In this study, the construction-soil micro gradient transect method, which scaled down the original method to a micro scale, was adopted to research the dynamic features of the distribution of soil temperature and horizontal heat flux next to different orientations of construction external walls in autumn. In order to examine the construction-soil micro gradient transect method, some work still had to be completed, as detailed in the following sections, including Sections 3.1.1, 3.1.2 and 3.1.3.

\subsubsection{Equal horizontal heat impact along parallel lines of construction baseline}

The construction baseline and a line along its parallel $(0.1 \mathrm{~m}$ from the construction baseline) were selected to verify equal horizontal heat impact along parallel lines of construction baseline. Eight sample points were set along each of the two lines (spatial span was $20 \mathrm{~m}$, Fig. 2); temperature of the surface soil layer 


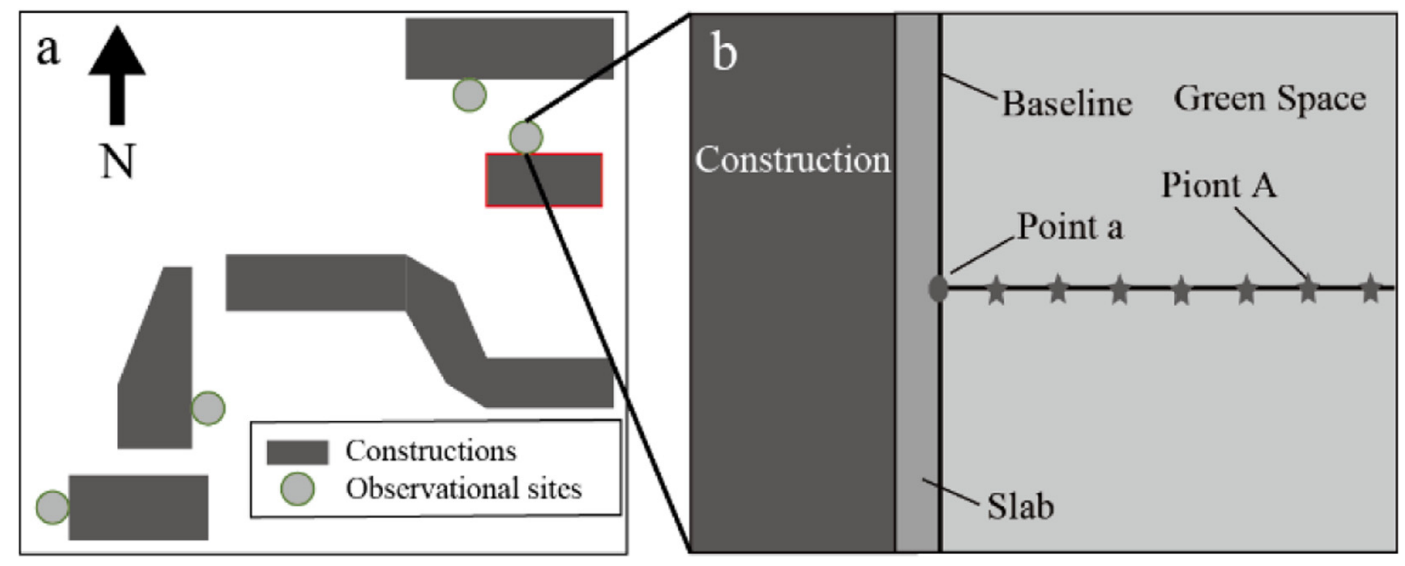

Fig. 1. Site condition and layout of the construction-soil micro gradient transect.

Table 1

Conditions of selected Observation sites.

\begin{tabular}{|c|c|c|c|c|c|c|c|c|c|c|}
\hline \multirow[t]{2}{*}{ Location } & \multicolumn{3}{|c|}{ Construction size } & \multicolumn{4}{|c|}{ Green space condition } & \multicolumn{3}{|c|}{ Meteorological condition } \\
\hline & Length $(\mathrm{m})$ & Width (m) & Height (m) & Land cover & Length $(\mathrm{m})$ & Width (m) & Duration of sunshine & Weather & At $(\mathrm{K})$ & $\mathrm{RH}(\%)$ \\
\hline \multirow[t]{2}{*}{ South } & 66 & 18 & 21 & Grass & 61 & 21 & $8: 30-16: 00$ & Sunny & $283-297$ & $18-79$ \\
\hline & & & & & & & & Cloudy & $286-295$ & $44-93$ \\
\hline \multirow[t]{2}{*}{ North } & 48 & 12 & 18 & Grass & 61 & 21 & $16: 00-17: 30$ & Sunny & $280-291$ & $22-68$ \\
\hline & & & & & & & & Cloudy & $280-290$ & $33-80$ \\
\hline \multirow[t]{2}{*}{ East } & 56 & $10-28$ & 28 & Grass & 56 & 2 & $9: 30-11: 30$ & Sunny & $282-296$ & $27-81$ \\
\hline & & & & & & & & Cloudy & $287-289$ & $58-81$ \\
\hline \multirow[t]{2}{*}{ West } & 54 & 16 & 40 & Grass & 16 & 4 & $11: 30-16: 30$ & Sunny & $282-298$ & $14-76$ \\
\hline & & & & & & & & Cloudy & $284-297$ & $38-87$ \\
\hline
\end{tabular}

Note: AT is air temperature and RH is relative humidity.

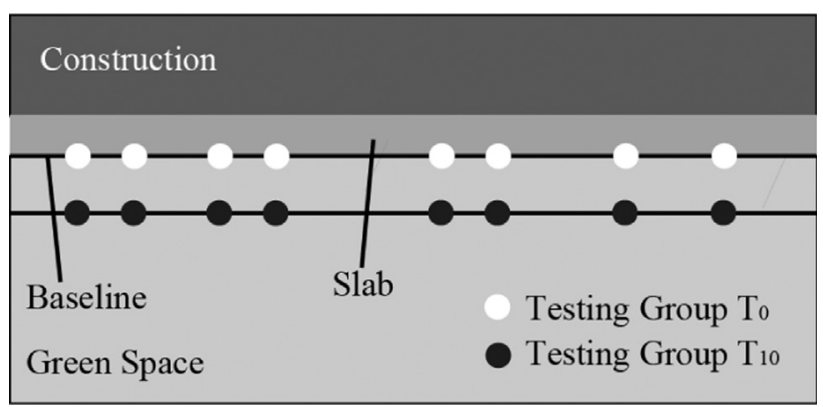

Fig. 2. Layout of testing groups.

(hereafter called soil temperature) of every sample point was investigated in triplicate at a depth of $0-0.025 \mathrm{~m}$, and the two testing groups were recorded as $\mathrm{T}_{0}$ and $\mathrm{T}_{10}$. The difference between $\mathrm{T}_{0}$ and $\mathrm{T}_{10}$ was calculated and recorded as $\Delta \mathrm{T}_{0-10}$. The calculated $\Delta \mathrm{T}_{0-10}$ of the eight groups was analyzed statistically to verify whether the horizontal heat impact along parallel lines of the construction baseline were equal.

Data were analyzed using a one-way ANOVA. The result showed that in a 20-m span of space, the $\Delta \mathrm{T}_{0-10}$ of the eight groups were not the same (Fig. 3), but no significant difference was found among them $(P>0.05)$.

Therefore, the results suggested that difference in soil temperature did not change with different observation points along any two parallel lines of the construction baseline. They also suggested that the distribution of soil temperature along any perpendicular line of construction baseline could represent the distribution of soil temperature of the whole green space next to the construction.

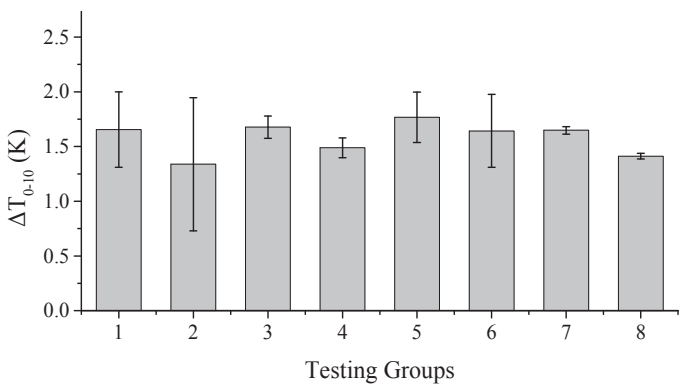

Fig. 3. Equal horizontal heat impact along parallel lines of construction baseline.

\subsubsection{Length of the construction-soil micro gradient transect}

The soil temperature changed significantly at the first $0.3 \mathrm{~m}$ from the heat source in an experiment in which soil was heated at one end of pipes for different hours (Shao et al., 2006). Therefore, it was determined that the maximum scope of horizontal heat impact of constructions was within 0.3 . Thus, 0.3 was taken as the tentative maximum scope of horizontal heat impact of constructions, but a more accurate number will be calculated in next study. Then, any other observation points that were further than $0.3 \mathrm{~m}$ were regarded as controls. Hence, the observation points along the construction-soil micro gradient transect (CSMGT) were set; 0 , $0.05,0.1,0.15,0.2,0.3,0.5$ and $0.7 \mathrm{~m}$ were selected as observation points (Fig. 1b); denser observation points at the first $0.3 \mathrm{~m}$ were used to determine changes in the scope of the horizontal heat impact, whereas more sparse observation points after the first $0.3 \mathrm{~m}$ were used as references. Soil temperatures were recorded as $\mathrm{T}_{0}, \mathrm{~T}_{5}, \mathrm{~T}_{10}, \mathrm{~T}_{15}, \mathrm{~T}_{20}, \mathrm{~T}_{30}, \mathrm{~T}_{50}$ and $\mathrm{T}_{70}$, respectively. 


\subsubsection{In situ observation}

In situ observations are widely applied in ecological studies with reliable results (Dorigo et al., 2011; Holmes et al., 2012; Su et al., 2011; Wallenstein et al., 2011). Based on the above results, the distribution of soil temperature along the construction-soil micro gradient transect can represent the distribution of soil temperature of the whole green space next to the side external wall. Therefore, in situ observation was adopted to investigate the continuous changing soil temperature of every observation point along the construction-soil micro gradient transect.

\subsection{Data collection}

The soil temperature was observed with soil temperature sensors (with a $0.2 \mathrm{~K}$ accuracy) and stored with data loggers. The sampling interval was set to be $30 \mathrm{~s}$, and the logging interval was set to be $1 \mathrm{~min}$. Thus, 60 values of soil temperature were acquired for every sensor during a one hour period (0-59th minute). These data were divided into six groups by time, and each group included 10 values. Then, the 10 values were averaged. Thus, 6 numerical values for every sensor were acquired in one hour and grouped as samples for this hour.

Meteorological data were recorded by a weather station, including air temperature, relative humidity, solar radiation, net radiation, and the horizontal heat flux between construction and soil. All of the meteorological data sampling intervals were set to be $1 \mathrm{~min}$, and the logging interval was set to be $10 \mathrm{~min}$. The sensors for air temperature, relative humidity and solar radiation were set at $2 \mathrm{~m}$ above the ground. The soil heat flux plate was set at a depth of 0-0.1 $\mathrm{m}$, at the construction baseline, with the top facing the construction and the bottom facing the soil (Fig. 4).

\subsection{Data processing}

One-way ANOVA was adopted in this research to analyze the differences among these observation points hour by hour. According to Section 3.1, the distribution of soil temperature along the construction-soil micro gradient transect is supposed to be a downwards curve under ideal conditions; observation points that are close to the construction baseline hold higher temperatures than observation points far away from the construction baseline. If a significant difference between two neighboring observation points is found, horizontal heat impact exists, and vice versa. The degree of significant difference is associated with the size of the scope of the horizontal heat impact. If the soil temperature of a later observation point is higher than that of a former observation point or the difference between the two observation points is less than $0.2 \mathrm{~K}$, the horizontal heat impact ceases. A correlation analysis was used to analyze the relationship between soil temperature difference and horizontal heat flux. The least squares method was used to create a formulation between the horizontal heat impact and the soil temperature difference. A two tail T-test was applied to analyze the significant differences between the value of simulation and the measurement, and the confidence band was set at $95 \%$.

\section{Results}

\subsection{Diurnal distribution of soil temperature next to external walls of different side in different weather conditions}

Under both sunny and cloudy conditions in autumn, the distributions of soil temperature along the construction-soil micro gradient transect next to different external side walls generally exhibited downward and wavy trends every hour (Fig. 5).

The observation period was set to exactly $24 \mathrm{~h}$, from 6:00 to 5:59 next day. Due to limitation of space, not all observation points or horary results were collected, but only a portion of them were collected. The letters a and b represent the south side external wall, $\mathrm{c}$ and $\mathrm{d}$ represent the north side external wall, e and f represent the east side external wall, and $g$ and $h$ represent the west side external wall in sunny and cloudy conditions, respectively (Fig. 5).

The highest soil temperature was recorded at 13:00-14:00 for the south side external wall in both sunny and cloudy conditions; for the north side external wall, it occurred at 15:00 in both sunny and cloudy conditions; it appeared at 11:00 on sunny days and 14:00 on cloudy days for the east side external wall; and it appeared at approximately 13:00-15:00 for the west side external wall in both sunny and cloudy conditions.

Generally speaking, the distributions of soil temperature showed downward trends along the construction-soil micro gradient transect next to different external side walls. However, some timestamps during which downward trends were disturbed still existed, such as the distribution of soil temperature next to the west side external wall at 12:00 in sunny weather (Fig. 5g). This
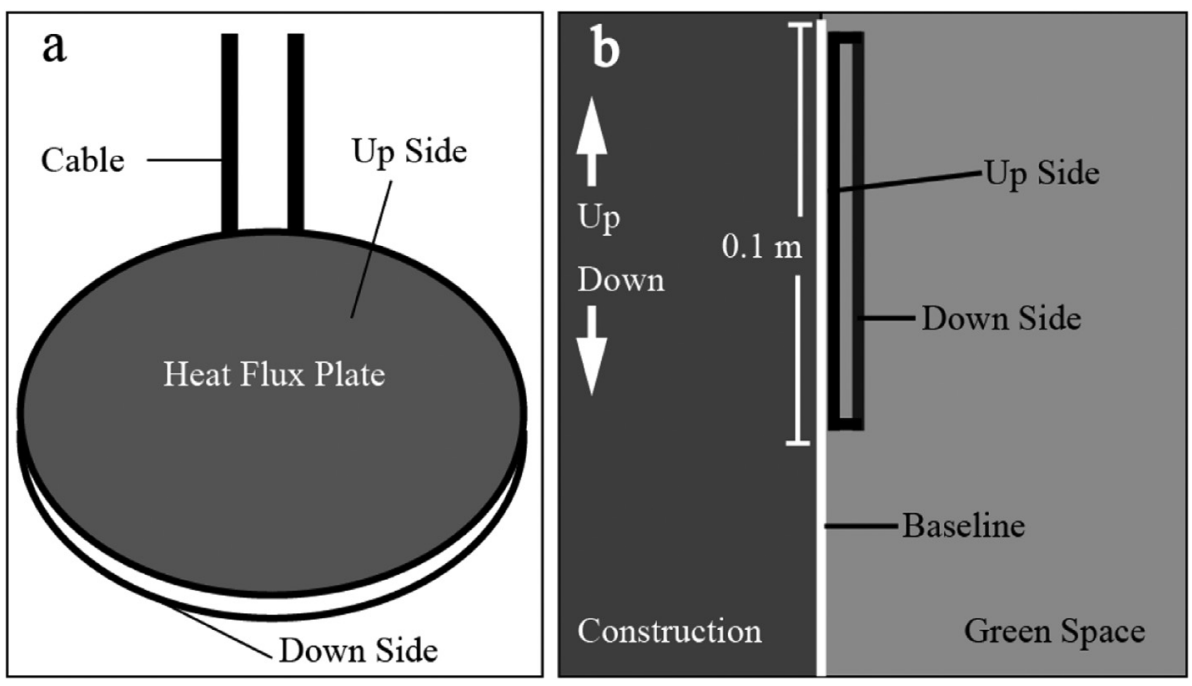

Fig. 4. Heat flux plate setting. 


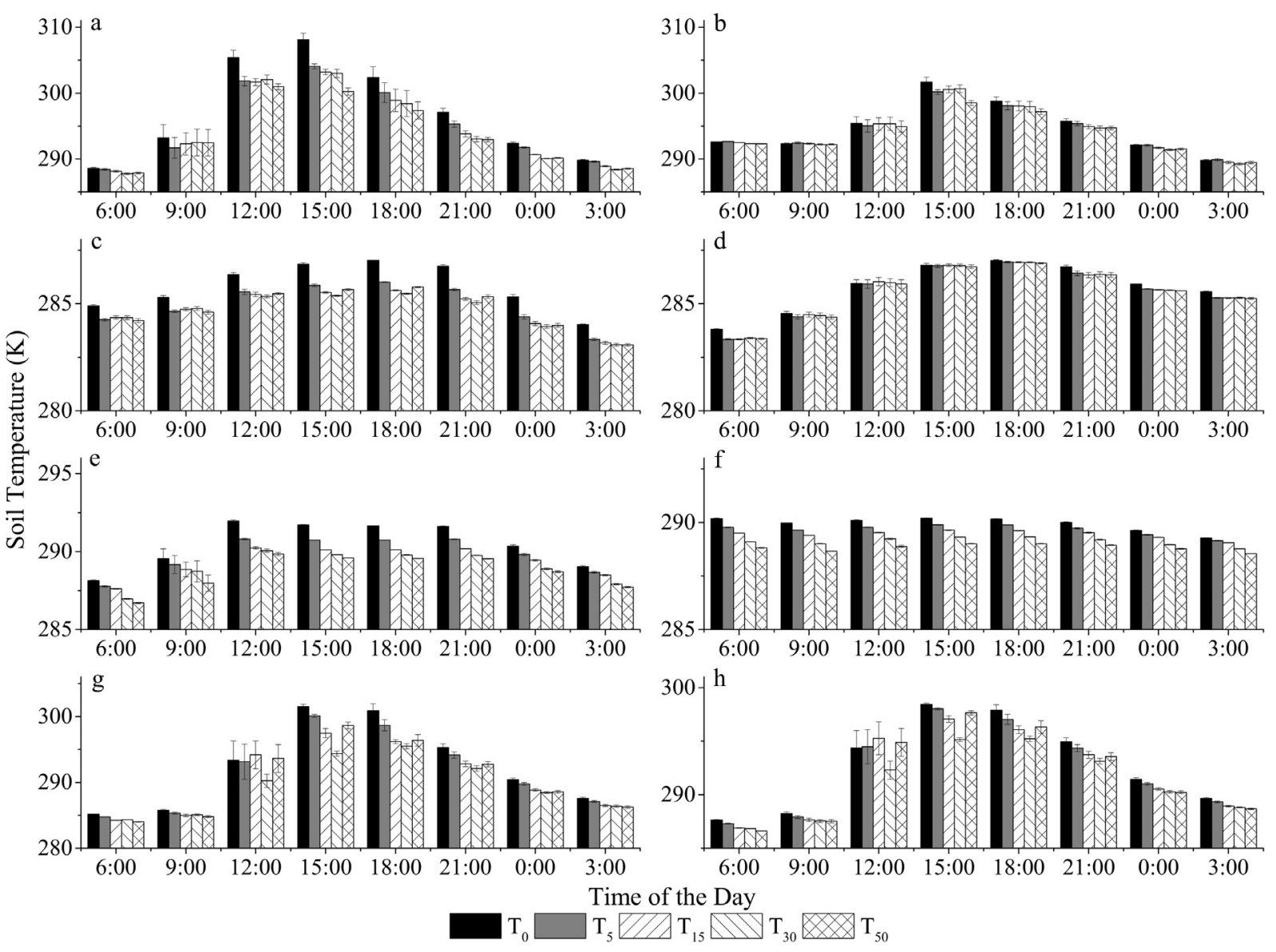

Fig. 5. Distributions of soil temperature along the CSMGT next to different side external walls in different weather conditions.

period just appeared at the moment when soil temperature raised drastically. Table 2 shows the time span during which the soil temperature increased drastically.

Table 2 indicates that the time spans of drastic increases in soil temperature were different for different side external walls in conditions of different weather. Between sunny and cloudy days, the time spans of drastic increases in soil temperature correlated with the period of receiving direct sunshine, except for the north side external wall.

\subsection{Scope of horizontal heat impact}

Using the construction-soil micro gradient transect method, the scope of horizontal heat impact was obtained and averaged during

Table 2

Change rate of soil temperature.

\begin{tabular}{llrllllll}
\hline \multirow{2}{*}{ Orientation } & Weather & Time span & \multicolumn{6}{c}{ Change rate of soil temperature $(\mathrm{K} / \mathrm{h})$} \\
\cline { 4 - 9 } & & & $\Delta \mathrm{T}_{0}$ & $\Delta \mathrm{T}_{5}$ & $\Delta \mathrm{T}_{15}$ & $\Delta \mathrm{T}_{30}$ & $\Delta \mathrm{T}_{50}$ & $\Delta \mathrm{T}_{\mathrm{m}}$ \\
\hline \multirow{2}{*}{ South } & Sunny & $8: 00-12: 00$ & 4.12 & 3.33 & 3.35 & 3.50 & 3.22 & 3.50 \\
& Cloudy & $11: 00-14: 00$ & 2.98 & 2.48 & 2.61 & 2.68 & 1.99 & 2.55 \\
\multirow{3}{*}{ Earth } & Sunny & $10: 00-12: 00$ & 0.39 & 0.40 & 0.30 & 0.24 & 0.32 & 0.33 \\
& Cloudy & $10: 00-13: 00$ & 0.32 & 0.29 & 0.25 & 0.25 & 0.29 & 0.28 \\
\multirow{3}{*}{ West } & Sunny & $9: 00-11: 00$ & 1.64 & 1.40 & 1.27 & 1.59 & 1.50 & 1.48 \\
& Cloudy & $10: 00-12: 00$ & 0.10 & 0.09 & 0.09 & 0.12 & 0.13 & 0.11 \\
& Sunny & $11: 00-13: 00$ & 6.13 & 5.99 & 5.85 & 3.41 & 5.78 & 5.43 \\
& Cloudy & $11: 00-13: 00$ & 3.83 & 3.90 & 3.99 & 2.63 & 3.80 & 3.63
\end{tabular}

Note: $\Delta \mathrm{T}_{\mathrm{m}}$ represents the average change rate of soil temperature along the CSMGT, calculated as $\Delta \mathrm{T}_{\mathrm{m}}=\left(\Delta \mathrm{T}_{0}+\Delta \mathrm{T}_{5}+\Delta \mathrm{T}_{15}+\Delta \mathrm{T}_{30}+\Delta \mathrm{T}_{50}\right) / 5$. the observation and was recorded as HSI. All HSI values changed with time on a diurnal scale (Fig. 6).

The continuous dynamic feature of the scope of horizontal heat impact was performed to represent the diurnal changes in autumn (Fig. 6). Changes in HSI for north, east and west exhibited wavy curves; all of them increased first and then went down. Comparing the three curves, the maximum appeared at different timestamps on a diurnal scale. For the south side external wall, however, the opposite situation appeared: the curve first went down and then increased up. The maximum scope of horizontal heat impact reaches $0.15,0.0167,0.1$ and $0.05 \mathrm{~m}$ for south, north, east and west, respectively.

\subsection{Distribution of mean temperature of the surface soil layer}

Along the construction-soil micro gradient transect next to different side walls, the soil temperature of adjacent green space was investigated continuously for a couple of days (Table 3); the data were reliant upon the meteorological conditions, and thus, data on whether sunny and cloudy days occurred were included.

Based on the continuous investigations, the distributions in mean soil temperature were calculated. The mean soil temperature was defined as the average soil temperature of each observation point during the period of observation. The distribution of mean soil temperature next to the four different side external walls exhibited a downward trend (Fig. 7).

The four downward trends suggested that the four side external walls were heat sources for the soil in adjacent green spaces. The 




Fig. 6. Changes of scope of horizontal heat impact next to different side external walls.

Table 3

Duration of observation.

\begin{tabular}{lc}
\hline Orientation & Duration \\
\hline South & $2013.9 .30-2013.10 .8$ \\
North & $2013.10 .14-2013.10 .19$ \\
East & $2013.10 .10-2013.10 .13$ \\
West & $2013.9 .25-2013.9 .28$ \\
\hline
\end{tabular}

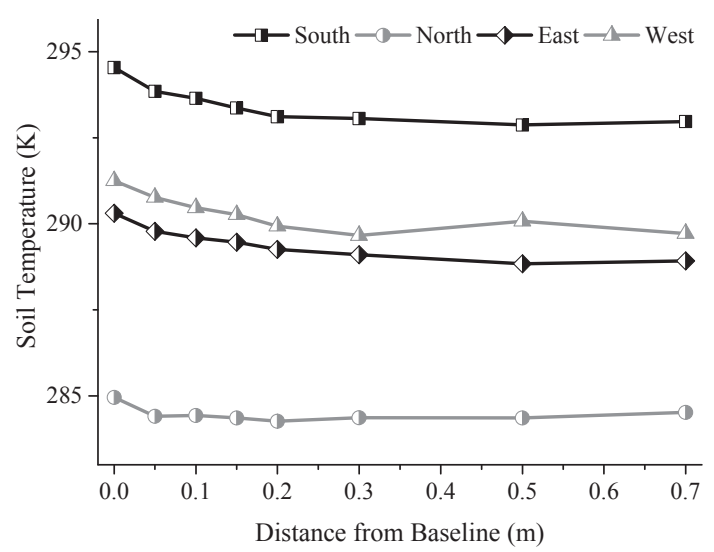

Fig. 7. Distributions of mean soil temperature along the CSMGT.

change rate of soil temperature for every side external wall can be calculated as follows:

$\mathrm{R}=\left(\mathrm{T}_{0 \mathrm{~m}}-\mathrm{T}_{70 \mathrm{~m}}\right) / \mathrm{D}$

Where $\mathrm{R}$ is the change rate of soil temperature, $\mathrm{T}_{0 \mathrm{~m}}$ and $\mathrm{T}_{70 \mathrm{~m}}$ are the mean soil temperature at the Observation points $0 \mathrm{~m}$ and $0.7 \mathrm{~m}$, and $\mathrm{D}$ is the distance between $0 \mathrm{~m}$ and $0.7 \mathrm{~m}$; here, $\mathrm{D}$ is $0.7 \mathrm{~m}$.
Along the construction-soil micro gradient transect, the change rates of mean soil temperature were $2.24,0.63,1.98$ and $2.19 \mathrm{~K} / \mathrm{m}$ for the south, north, east and west side external walls, respectively. These values suggest that the intensity of the horizontal heat impact of constructions for the four side external walls could be ranked as south, west, east and north.

\subsection{Horizontal heat flux and the difference between $T_{0}$ and $T_{5}$}

The horizontal heat flux between construction and soil can be investigated with a heat flux plate. Currently, the accuracy of a heat flux plate is between $-15 \%$ and $+5 \%$; the error is large, and the accuracy is low. However, a heat flux plate with self-correction function improves the accuracy to $\pm 5 \%$, making it the most accurate for now. However, this type of heat flux plate has to be only used by connecting with a data logger from a weather station, which runs a special program and usually links with other types of sensors. Investigating the horizontal heat flux between a construction and soil as the study requires is not convenient. Therefore, a method that can be used to accurately estimate the horizontal heat flux between a construction and the soil needs to be determined.

Heat flux is generated by the difference in soil temperature between different soil layers. In this study, a heat flux plate with a self-correction function was set between 0 and $0.05 \mathrm{~m}$ along the construction-soil micro gradient transect. Horizontal heat flux between a construction and the soil, recorded as $\mathrm{G}_{\mathrm{h}}$, and the difference in soil temperature between $\mathrm{T}_{0}$ and $\mathrm{T}_{5}$, recorded as $\Delta \mathrm{T}$, were formulated together. A correlation analysis was used to analyze the relationship between $G_{h}$ and $\Delta T$. An extreme significant correlation was found $(P<0.001)$. The least squares method was used to create a formulation between $G_{h}$ and $\Delta T$. Weather conditions and soil moisture during the experimental session are shown in Table 4.

$\mathrm{G}_{\mathrm{h}}$ and $\Delta \mathrm{T}$ values were investigated and calculated in different weather conditions (Table 4). The fitting formulation was $\mathrm{G}_{\mathrm{h}}=31.77 \Delta \mathrm{T}+8.11$, the SSE was $1.958 \mathrm{e}+04$ and the RMSE was 
Table 4

Details of weather conditions.

\begin{tabular}{|c|c|c|c|c|c|c|c|c|}
\hline Sample & $\mathrm{WD}_{\mathrm{m}}$ & $\mathrm{NR}_{\mathrm{m}}$ & $\mathrm{AT}_{\text {min }}$ & $\mathrm{AT}_{\max }$ & $\mathrm{SM}_{\text {min }}$ & $\mathrm{SM}_{\max }$ & $\mathrm{SR}_{\text {sum }}$ & $\mathrm{P}_{\text {sum }}$ \\
\hline Day & $(\mathrm{M} / \mathrm{S})$ & $\left(\mathrm{W} / \mathrm{m}^{2}\right)$ & $(\mathrm{K})$ & $(\mathrm{K})$ & $(\%)$ & $(\%)$ & $\left(\mathrm{KJ} / \mathrm{m}^{2}\right)$ & $(\mathrm{mm})$ \\
\hline 1 & 0.39 & 140.96 & 297.72 & 308.79 & 9 & 31 & 18785.4 & 0.00 \\
\hline 2 & 0.44 & 73.22 & 293.78 & 305.41 & 25 & 28 & 19240.2 & 7.37 \\
\hline 3 & 0.26 & -1.10 & 294.2 & 299.7 & 26 & 28 & 11312.4 & 1.27 \\
\hline 4 & 0.26 & 55.91 & 296.56 & 303.74 & 25 & 28 & 4059 & 0.00 \\
\hline 5 & 0.35 & 118.98 & 296.43 & 307 & 23 & 28 & 8329.8 & 0.00 \\
\hline 6 & 0.38 & 120.16 & 297.78 & 305.72 & 18 & 27 & 16,194 & 0.00 \\
\hline 7 & 0.39 & 75.17 & 297.98 & 305.76 & 17 & 26 & 16,734 & 0.00 \\
\hline Verification & 0.35 & 124.15 & 297.14 & 308.13 & 9 & 17 & 10,419 & 0.00 \\
\hline
\end{tabular}

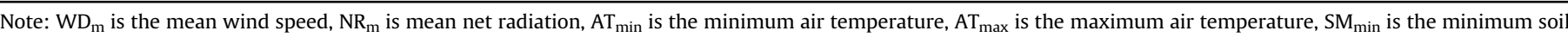

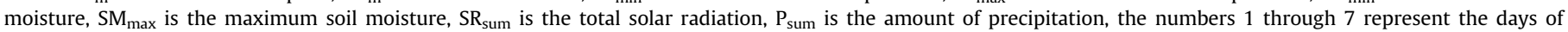
experiment, and verification is the day when the fitting formulation was verified.

4.96, meaning that the fit of the relevance and precision was high enough to estimate the horizontal heat flux between a construction and the soil (Fig. 8).

According to the results (Fig. 9), the value of simulation and observation were compared to verify the reliability of this formulation using a two-tailed $\mathrm{T}$ test. The time period selected was from 6:00 to 5:00 the next day. The two-tailed T test results showed no significant difference between the value of simulation and measurement $(P>0.05$, Fig. 9).

From the above data, the generated formulation, $\mathrm{G}_{\mathrm{h}}=31.77 \Delta \mathrm{T}+8.11$, was accurate enough to estimate the horizontal heat flux between a construction and the soil. In addition, based on the observation results in Section 4.2 (Fig. 6), the maximum and minimum $\Delta \mathrm{T}$ values for the four side external walls on a diurnal scale were calculated along with the maximum, minimum and mean horizontal heat flux for every side external wall (Table 5). The mean horizontal heat flux was the average of the horizontal heat flux on a diurnal scale.

The maximum horizontal heat flux between a construction and the soil were different with changes in different side external walls during similar weather conditions, and they were also different at the same side external wall in different weather conditions. A similar situation was observed with the minimum and mean horizontal heat flux between a construction and the soil.



Fig. 8. Curve fitting.

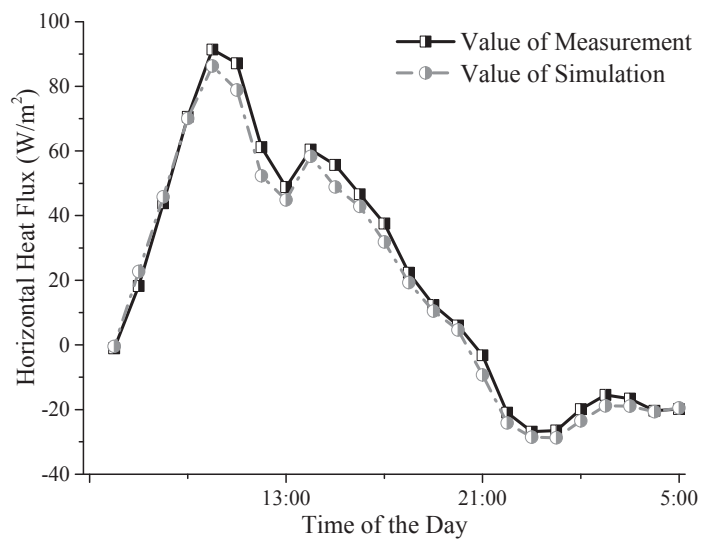

Fig. 9. Comparison of values of simulation and measurement.

Table 5

Soil temperature difference and horizontal heat flux simulation.

\begin{tabular}{|c|c|c|c|c|c|c|c|}
\hline \multirow[t]{2}{*}{ Orientation } & \multirow[t]{2}{*}{ Weather } & \multicolumn{3}{|l|}{$\Delta \mathrm{T}(\mathrm{K})$} & \multicolumn{3}{|c|}{$\mathrm{G}\left(\mathrm{W} / \mathrm{m}^{2}\right)$} \\
\hline & & Max & Min & Mean & Max & Min & Mean \\
\hline \multirow[t]{2}{*}{ South } & Sunny & 4.3400 & 0.1300 & 1.1228 & 146.70 & 12.48 & 44.13 \\
\hline & Cloudy & 1.4937 & -0.1463 & -0.0400 & 55.96 & 3.67 & 7.07 \\
\hline \multirow[t]{2}{*}{ North } & Sunny & 1.1533 & 0.2825 & 0.6214 & 45.11 & 17.35 & 28.15 \\
\hline & Cloudy & 0.4085 & 0.1075 & 0.0277 & 21.36 & 11.77 & 9.22 \\
\hline \multirow[t]{2}{*}{ East } & Sunny & 1.0925 & 0.6233 & 0.4014 & 43.17 & 28.21 & 21.14 \\
\hline & Cloudy & 0.5628 & 0.0160 & 0.0413 & 26.28 & 8.85 & 9.66 \\
\hline \multirow[t]{2}{*}{ West } & Sunny & 2.2113 & 0.2275 & 0.5043 & 78.84 & 15.59 & 24.42 \\
\hline & Cloudy & 0.8527 & -0.1035 & 0.1631 & 35.52 & 5.04 & 13.54 \\
\hline
\end{tabular}

\subsection{Distribution of horizontal heat flux at every range interval along the CSMGT}

Based on the distribution of mean soil temperature along the construction-soil micro gradient next to different side external walls, the difference of soil temperature at every spatial sampling interval was calculated. Combined with the generated formulation in Section 4.4, the mean horizontal heat flux between a construction and the soil was calculated (Fig. 10).

In general, for the four different side external walls, the mean horizontal heat flux between a construction and the soil showed 


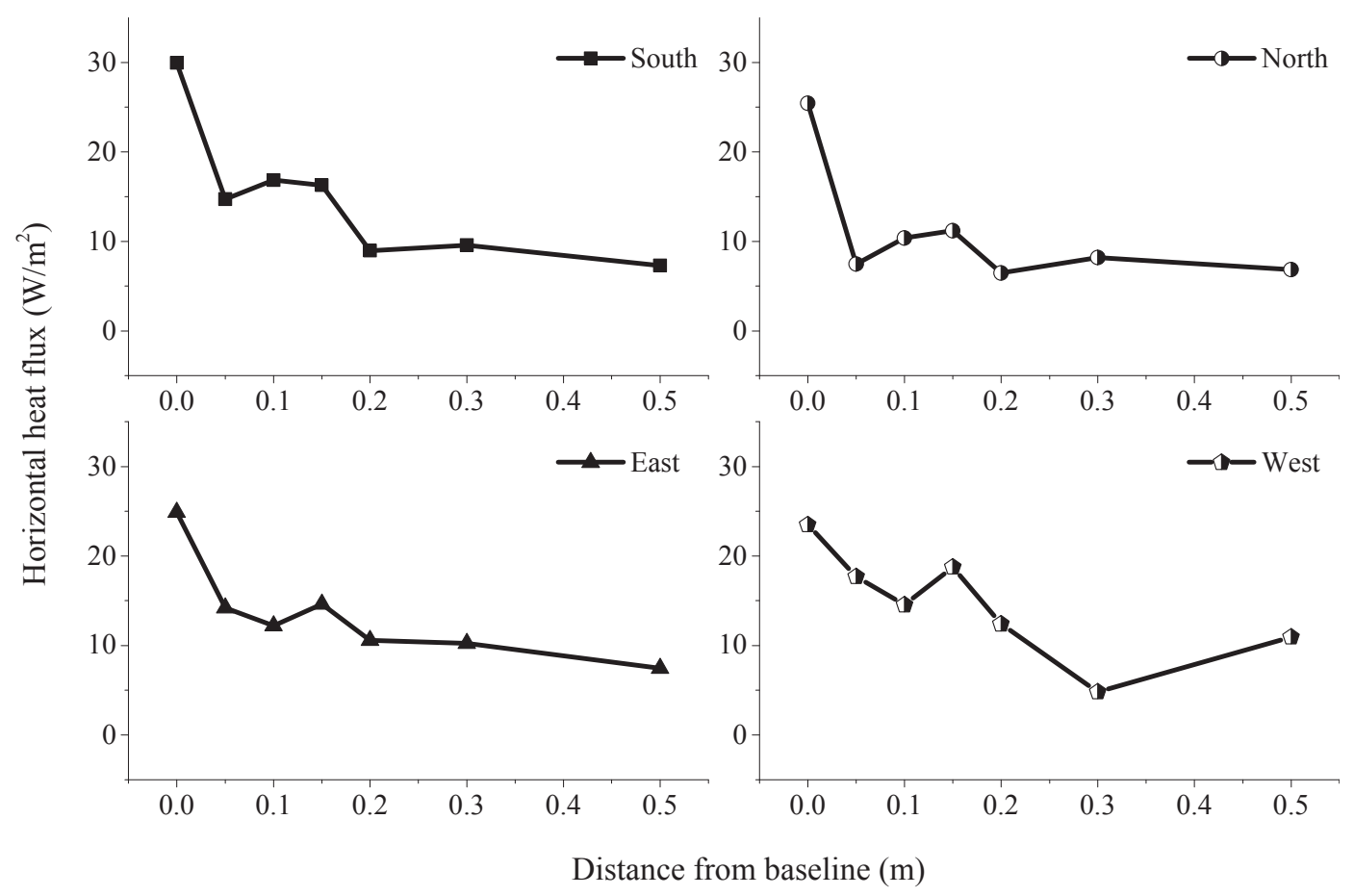

Fig. 10. Distribution of horizontal heat flux.

downward trends along the construction-soil micro gradient. Theoretically, the horizontal heat flux between a construction and the soil should show a stable downward trend, whereas realistically it showed a wavy trend. For the south side external wall, the horizontal heat flux peaked at $29.94 \mathrm{~W} / \mathrm{m}^{2}$ and exhibited a low of $7.31 \mathrm{~W} / \mathrm{m}^{2}$; for the north side external wall, it peaked at $25.44 \mathrm{~W} /$ $\mathrm{m}^{2}$ and exhibited a low of $6.46 \mathrm{~W} / \mathrm{m}^{2}$; for the east side external wall, it peaked at $24.87 \mathrm{~W} / \mathrm{m}^{2}$ and exhibited a low of $7.45 \mathrm{~W} / \mathrm{m}^{2}$; and for the west side external wall, it peaked at $23.50 \mathrm{~W} / \mathrm{m}^{2}$ and exhibited a low of $4.81 \mathrm{~W} / \mathrm{m}^{2}$.

\section{Discussion}

\subsection{Distribution and change rate of soil temperature along the CSMGT}

Soil temperature is influenced by many environmental factors, including solar radiation, air temperature, soil texture, soil moisture, altitude, latitude, slope and shade (Lv and Li, 2006), thus, any factor that can influence soil temperature can lead to different distributions of soil temperature. However, this study was conducted on a very small scale; the length of the construction-soil micro gradient is only $0.7 \mathrm{~m}$, and the longest distance between sample areas is only $192 \mathrm{~m}$, therefore, soil texture, altitude and latitude were not considered as factors able to influence soil temperature.

Due to geometrical shaped constructions, different side external walls and their adjacent soil shared different sunshine and shade duration. During sunshine, soil temperature was influenced by solar radiation, long-wave radiation and atmospheric radiation, whereas without sunshine, soil temperature was influenced by only long-wave radiation and atmospheric radiation. Sunshine duration for every side external wall and its adjacent soil is different, causing a difference in soil temperature next to different side external walls and also the different periods and extent of soil temperature increase, as shown in Table 2.
For a single side external wall, the soil temperature gradient is formed by a combination of multiple factors. The genesis of a soil temperature gradient is the horizontal heat flux. In this study, the soil temperatures changed drastically in the first $0.2 \mathrm{~m}$ along the construction-soil micro gradient. Thus, two horizontal heat flux plates were placed at two observation points $(0 \mathrm{~m}$ and $0.2 \mathrm{~m}$ from the construction baseline along the construction-soil micro gradient) to investigate and compare the horizontal heat flux of the two observation points, recorded as $\mathrm{HHF}_{0}$ and $\mathrm{HHF}_{20}$.

Along the construction-soil micro gradient transect, $\mathrm{HHF}_{0}$ and $\mathrm{HHF}_{20}$ showed different orders of magnitude (Fig. 11); $\mathrm{HHF}_{0}$ fluctuated between -5.58 and $98.27 \mathrm{~W} / \mathrm{m}^{2}$, and the average value was $33.88 \mathrm{~W} / \mathrm{m}^{2}$, whereas $\mathrm{HHF}_{20}$ fluctuated between -2.76 and $2.68 \mathrm{~W} /$ $\mathrm{m}^{2}$ and exhibited an average value of $0.50 \mathrm{~W} / \mathrm{m}^{2}$. This evidence indicated that soil temperature was not only influenced by solar radiation, long-wave radiation and atmospheric radiation along the construction-soil micro gradient but also by the horizontal heat flux between a construction and the soil. Therefore, the soil temperature was higher in the first $0.2 \mathrm{~m}$ along the construction-soil micro gradient transect and a soil temperature gradient emerged.

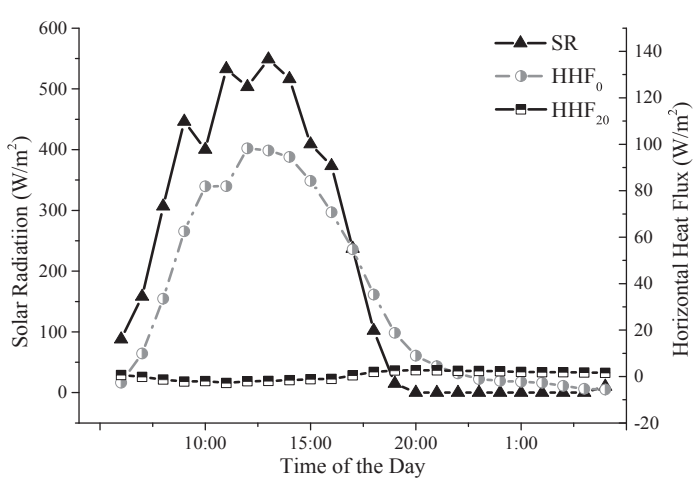

Fig. 11. Diurnal changes of $\mathrm{SR}, \mathrm{HHF}_{0}$ and $\mathrm{HHF}_{20}$. 


\subsection{Changes in the scope of horizontal heat impact}

For the four different side external walls, changes in the scope of horizontal heat impact acted as wavy curves, but the trends were different; for the south side external wall, it decreased first and then increased during the interval between 6:00 and 5:59 the next day, whereas for the other three side external walls, the situation was opposite. The minimum scope of the horizontal heat impact was none (no horizontal heat impact) or $0 \mathrm{~m}$. However, the maximum scope of the horizontal heat impact was $0.15,0.0167,0.1$ and $0.05 \mathrm{~m}$ for the south, north, east and west side external walls, respectively. In addition, the maximum scope of the horizontal heat impact appeared at 18:00, 14:00, 15:00 and 15:00 for the south, north, east and west side external walls, respectively, all of which showed a decrease in solar radiation, suggesting that the predominant role of solar radiation was weakening.

Because the heat flux plate was set at the construction baseline next to the south side external wall, only the construction-soil micro gradient transect next to the south side external wall is discussed and analyzed here. The maximum horizontal heat impact scope was only detected at nightfall or at night, and it lasted until dawn the next day. The maximum scope of horizontal heat impact disappeared and the soil temperature gradient was disturbed when sun shone on the ground. This phenomenon indicated that the dominant factor of soil temperature was solar radiation. Solar radiation was higher than horizontal heat flux during the day time than at night; at the timestamp of 7:00,12:00 and 16:00, the ratio of solar radiation and horizontal heat flux were 15.97, 5.12 and 5.27; when the sun was setting, solar radiation weakened, and the ratio was only 2.89; however, at night, no solar radiation was present, and the ratio was 0 . These results show that the horizontal heat flux took the place of dominant factor at nightfall, forming the soil temperature gradient along the construction-soil micro gradient transect for some time.

\subsection{Correlation between horizontal heat flux and meteorological factors}

Previous studies have shown that a significant correlation existed between net radiation and vertical soil heat flux (Idso et al., 1975), as well as solar radiation and vertical soil heat flux on a diurnal scale (Li et al., 2012). In this study, a similar result was found; an extreme significant correlation between horizontal heat flux and net radiation was found on a diurnal scale $(P<0.001)$, as well as between horizontal heat flux and solar radiation $(\mathrm{P}<0.001$, Fig 12).

However, the linear fit result on a diurnal scale was not accurate enough to simulate the horizontal heat flux via net radiation $\left(R^{2}\right.$ is

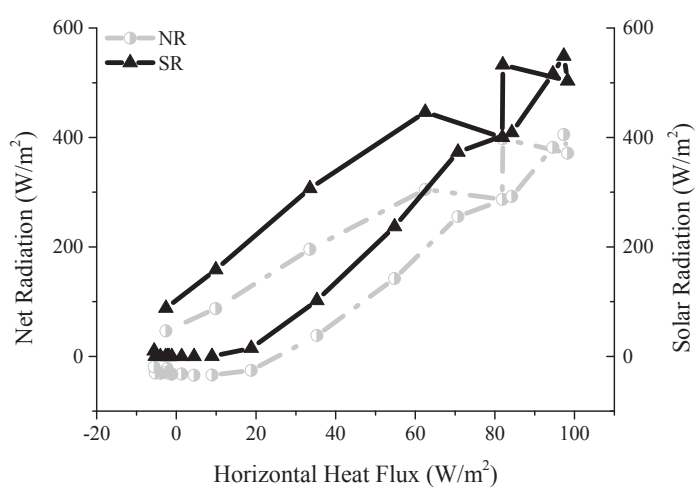

Fig. 12. Correlation between horizontal heat flux and net/solar radiation.
0.915) or solar radiation $\left(R^{2}\right.$ is 0.921$)$, not mention on a long term scale. Among all of our available data, only soil temperature differences between $T_{0}$ and $T_{5}$ and the horizontal heat flux acquire the most accurate result.

\subsection{Distribution of the horizontal heat flux along the CSMGT}

Spatial heterogeneity is one of most striking features of soil. A similar situation occurs in urban areas, due to a series of influence caused by anthropogenic activities (Irwin and Bockstael, 2007; Pickett and Cadenasso, 2009). Spatial heterogeneities includes many aspects, such as porosity, water content, and carbon and nitrogen content, even at a small scale (Liu et al., 2008; Stoyan et al., 2000; Wang and Wang, 2000). Porosity and water content could lead to different thermal properties of soil and then soil heat flux ( $\mathrm{Li}$ et al., 2003; Shao et al., 2006). Although quantities of studies that have focused on soil heat flux exist, horizontal heat flux has not been taken into account. In this study, horizontal heat flux was predicted to act as a stable downward curve and to become even and flat gradually. However, it showed insteadly a downward and wavy trend, which could be caused by spatial heterogeneity of soil on such a small spatial scale.

\section{Conclusions}

In this study, the observation method of the construction-soil micro gradient transect and statistical approaches were applied to investigate and analyze continuous changes in the temperature of the surface soil layer of green space adjacent to four different side external walls of constructions in conditions of two different weather conditions in autumn. The spatial scope of the construction-soil micro gradient transect was $0-0.7 \mathrm{~m}$. Our observations were conducted for 4-10 days, including two types of sunny and cloudy weather conditions. The conclusions are summarized as follows:

(1) For different side external walls, under the effect of construction geometric shape, temperature of the surface soil layer increases at different periods to different extents. In sunny weather, soil temperature increases most rapidly from $8: 00$ to $12: 00$ with a mean change rate of $3.50 \mathrm{~K} / \mathrm{h}$ for the south, from $10: 00$ to $12: 00$ with a mean change rate $0.33 \mathrm{~K} / \mathrm{h}$ for the north, from 9:00 to 11:00 with a mean change rate of $1.48 \mathrm{~K} / \mathrm{h}$ for the east and from 11:00 to $13: 00$ with a mean change rate of $5.43 \mathrm{~K} / \mathrm{h}$ for the west. However, in cloudy weather, soil temperature increases most rapidly from 11:00 to $14: 00$ with a mean change rate of $2.55 \mathrm{~K} / \mathrm{h}$ for the south, from 10:00 to $13: 00$ with a mean change rate of $0.28 \mathrm{~K} / \mathrm{h}$ for the north, from 10:00 to 12:00 with a mean change rate of $0.11 \mathrm{~K} / \mathrm{h}$ for the east and from 11:00 to $13: 00$ with a mean change rate of $3.63 \mathrm{~K} / \mathrm{h}$ for the west.

(2) Along the construction-soil micro gradient transect, the maximum construction horizontal heat impact scope for the four side external walls are $0.15 \mathrm{~m}$ for the south, $0.0167 \mathrm{~m}$ for the north, $0.1 \mathrm{~m}$ for the east and $0.05 \mathrm{~m}$ for the west in autumn; however, the minimum construction horizontal heat impact scope for the four side external walls are none or $0 \mathrm{~m}$, meaning no or weak horizontal heat impact.

(3) The distribution of mean temperatures of the surface soil layer along the construction-soil micro gradient transect next to different side external walls all show a downward trend; however, the soil temperature gradient was different, at $2.24 \mathrm{~K} / \mathrm{m}$ for the south, $0.63 \mathrm{~K} / \mathrm{m}$ for the north, $1.98 \mathrm{~K} / \mathrm{m}$ for the east and $2.19 \mathrm{~K} / \mathrm{m}$ for west. 
(4) The formula $G=31.77 \Delta T+8.11\left(P<0.001, R^{2}\right.$ is 0.9759$)$ was generated to simulate horizontal heat flux between a construction and the soil at the soil surface layer. According to the formulation, on a diurnal scale, the mean horizontal heat flux was $44.13,28.15,21.14$ and $24.42 \mathrm{~W} / \mathrm{m}^{2}$ for the south, north, east and west side external walls, respectively, in sunny weather, whereas it is $7.07,9.22,9.66$ and $13.54 \mathrm{~W} / \mathrm{m}^{2}$ for the south, north, east and west side external walls, respectively, in cloudy weather. The distributions of the mean horizontal heat flux of autumn showed downward trends; the maximum was 29.94, 25.44, 24.87 and $23.50 \mathrm{~W} / \mathrm{m}^{2}$, and the minimum was $7.31,6.46,7.45$ and $4.81 \mathrm{~W} / \mathrm{m}^{2}$ for the south, north, east and west side external walls, respectively.

\section{Acknowledgment}

This research was supported by National Foundation of Natural Sciences of China (41171442, 70873121), the State Key Laboratory of Urban \& Regional Ecology (SKLURE2012-1-01) and the 135 Knowledge Innovation Project of Chinese Academy of Sciences (YSW2013-B04).

\section{References}

Bogren, J., Gustavsson, T., 1991. Nocturnal air and road surface temperature variations in complex terrain. Int. J. Climatol. 11, 443-455.

Delgado, J.D., Arroyo, N.L., Arévalo, J.R., Fernández-Palacios, J.M., 2007. Edge effects of roads on temperature, light, canopy cover, and canopy height in laurel and pine forests (Tenerife, Canary Islands). Landsc. Urban Plan. 81, 328-340.

Dorigo, W., Wagner, W., Hohensinn, R., Hahn, S., Paulik, C., Xaver, A., Gruber, A., Drusch, M., Mecklenburg, S., Oevelen, P.V., 2011. The International Soil Moisture Network: a data hosting facility for global in situ soil moisture measurements, Hydrol. Earth Syst. Sci. 15, 1675-1698.

Givoni, B., 2007. Cooled soil as a cooling source for buildings. Sol. Energy 81, $316-328$.

Grimm, N.B., Faeth, S.H., Golubiewski, N.E., Redman, C.L., Wu, J., Bai, X., Briggs, J.M., 2008. Global change and the ecology of cities. Science 319, 756-760.

Halverson, H., Heisler, G., 1981. Soil Temperatures under Urban Trees and Asphalt. In: USDA Forest Service Research Paper NE (USA). No. 481, pp. 1-9.

Holmes, T.R., Jackson, T.J., Reichle, R.H., Basara, J.B., 2012. An assessment of surface soil temperature products from numerical weather prediction models using ground-based measurements. Water Resour. Res. 48.

Idso, S.B., Aase, J.K., Jackson, R.D., 1975. Net radiation - soil heat flux relations as influenced by soil water content variations. Boundary-Layer Meteorol. 9, 113-122.

Irwin, E.G., Bockstael, N.E., 2007. The evolution of urban sprawl: evidence of spatial heterogeneity and increasing land fragmentation. Proc. Natl. Acad. Sci. 104, 20672-20677.

Jacinto, A.C., Villar, M.V., Gómez-Espina, R., Ledesma, A., 2009. Adaptation of the van Genuchten expression to the effects of temperature and density for compacted bentonites. Appl. Clay Sci. 42, 575-582.

Janssen, H., Carmeliet, J., Hens, H., 2004. The influence of soil moisture transfer on building heat loss via the ground. Build. Environ. 39, 825-836.
Landman, K., Delsante, A., 1987. Steady-state heat losses from a building floor slab with horizontal edge insulation. Build. Environ. 22, 57-60.

Landsberg, H.E., 1981. The Urban Climate. Academic Press, London.

Li, L., Zhang, H., Hu, B., Liu, G.-R., Liu, Z.-R., Wang, Y.-S., 2012. Characteristics of soil heat flux in different soil types in China. Plateau Meteorol. 31, 322-328.

Li, Y., Shao, M., Wang, W., Wang, Q., Zhang, J., Lai, J., 2003. Influence of soil textures on the thermal properties. Trans. CSAE 19, 62-65.

Liu, F., Wang, S., Luo, H., Liu, Y., Liu, H., 2008. Micro-habitats in karst forest ecosystem and variability of soils. Acta Pedol. Sin. 45, 1055-1062.

Luck, M., Wu, J., 2002. A gradient analysis of urban landscape pattern: a case study from the Phoenix metropolitan region, Arizona, USA. Landsc. Ecol. 17, 327-339.

Lv, Y.-Z., Li, B.-G., 2006. Pedology. China Agriculture Press, Beijing.

Mihalakakou, G., Santamouris, M., Asimakopoulos, D., Argiriou, A., 1995. On the ground temperature below buildings. Sol. Energy 55, 355-362.

Mount, H., Hernandez, L., Goddard, T., Indrick, S., 1999. Temperature Signatures for Anthropogenic Soils in New York City. USDANRCS, National Soil Survey Center, Lincoln.

Oke, T.R., 1982. The energetic basis of the urban heat island. Q. J. R. Meteorol. Soc. $108,1-24$.

Pickett, S.T., Cadenasso, M.L., 2009. Altered resources, disturbance, and heterogeneity: a framework for comparing urban and non-urban soils. Urban Ecosyst. 12, 23-44.

Pouyat, R., McDonnell, M., 1991. Heavy metal accumulations in forest soils along an urban-rural gradient in southeastern New York, USA. Water Air Soil Pollut. 57, 797-807.

Pouyat, R.V., McDonnell, M.J., Pickett, S., 1995. Soil characteristics of oak stands along an urban-rural land-use gradient. J. Environ. Qual. 24, 516-526.

Pouyat, R.V., Pataki, D.E., Belt, K.T., Groffman, P.M., Hom, J., Band, L.E., 2007. Effects of Urban Land-use Change on Biogeochemical Cycles, Terrestrial Ecosystems in a Changing World. Springer, pp. 45-58.

Shao, M.A., Wang, Q.J., Huang, M.B., 2006. Soil Physics. Higher Education Press, Beijing.

Shi, B., Tang, C., Gao, L., Jiang, H., Liu, C., 2012. Difference in shallow soil temperature at urban and rural areas. J. Eng. Geol. 20, 58-65.

Simões, N., Serra, C., 2012. Ground contact heat losses: simplified calculation method for residential buildings. Energy 48, 66-73.

Stoyan, H., De-Polli, H., Böhm, S., Robertson, G.P., Paul, E.A., 2000. Spatial heterogeneity of soil respiration and related properties at the plant scale. Plant Soil 222, 203-214.

Su, Z., Wen, J., Dente, L., Velde, R., Wang, L., Ma, Y., Yang, K., Hu, Z., 2011. The Tibetan Plateau observatory of plateau scale soil moisture and soil temperature (TibetObs) for quantifying uncertainties in coarse resolution satellite and model products. Hydrol. Earth Syst. Sci. 15, 2303-2316.

Tang, A.-M., Cui, Y.-J., 2005. Controlling suction by the vapour equilibrium technique at different temperatures and its application in determining the water retention properties of MX80 clay. Can. Geotech. J. 42, 287-296.

Tang, C.-S., Shi, B., Gao, L., Daniels, J.L., Jiang, H.-T., Liu, C., 2011. Urbanization effect on soil temperature in Nanjing, China. Energy Build. 43, 3090-3098.

Turkoglu, N., 2010. Analysis of urban effects on soil temperature in Ankara. Environ. Monit. Assess. 169, 439-450.

Wallenstein, M., Allison, S.D., Ernakovich, J., Steinweg, J.M., Sinsabaugh, R., 2011. Controls on the Temperature Sensitivity of Soil Enzymes: a Key Driver of In Situ Enzyme Activity Rates, Soil Enzymology. Springer, pp. 245-258.

Wang, Z., Wang, Q., 2000. The spatial heterogeneity of soil physical properties in forests. Acta Ecol. Sin. 20, 945-950.

Yang, J.H., 2006. The Influence of Highway Soil to the Growth of Plant and its Improvement Measures. Hebei Jiaotong Science and Technology, pp. 19-52.

Zhu, W.-X., Carreiro, M.M., 1999. Chemoautotrophic nitrification in acidic forest soils along an urban-to-rural transect. Soil Biol. Biochem. 31, 1091-1100. 